\title{
SISTEM DETEKSI KONDISI JALAN MENGGUNAKAN METODE Z-DIFF PADA SMARTPHONE ANDROID
}

\author{
Astrid Novita Putri ${ }^{1}$, Susanto $^{2}$, Siti Asmiatun ${ }^{3}$ \\ ${ }^{1,2}$ Program Studi Teknik Informatika, Fakultas Teknologi Informasi dan Komunikasi, \\ Universitas Semarang \\ Jl. Soekarno Hatta Tlogosari Semarang, Indonesia \\ Email : astrid@usm.ac.id ${ }^{1}$, susanto@usm.ac.id², siti.asmiatun@usm.ac.id ${ }^{3}$
}

\begin{abstract}
ABSTRAK
Kondisi jalan yang baik akan memberikan kenyamanan dan memperlancar aktifitas suatu daerah. Penggunaan transportasi darat di indonesia sendiri sangat tinggi. Hal ini menyebakan beban lalu lintas yang sangat tinggi dan mengakibatkan kerusakan pada jalan. Dalam melakukan upaya untuk mengurangi angka kecelakan dapat dilakukan dengan mengidentifikasi penyebab kecelakaan dan proses cara memperbaikinya. Salah satu faktor penyebab kecelakaaan adalah kondisi jalan yang berlubang. Salah satu solusi untuk mengurangi angka kecelakaan adalah dengan menyediakan informasi mengenai kondisi jalan berlubang kepada pihak dinas setempat. Sehingga dengan adanya informasi tersebut dinas setempat dapat segera menindaklanjuti perbaikan jalan. Berdasarkan dari beberapa penelitian sebelumnya yang berkaitan dengan masalah yang diangkat pada penelitian ini akan membahas tentang pengembangan perangkat lunak dengan memanfaatkan sensor accelerometers sebagai pencatat lokasi jalan berlubang yang ada di semarang timur. Penelitian ini menggunakan metode alghoritma Z-diff untuk menyaring data yang diperoleh dari sensor accelerometers. Dari hasil percobaan dibeberapa kecamatan semarang timur yang tergolong memiliki tingkat kerusakan jalan yang tinggi, penelitian ini menemukan 281 titik jalan berlubang. Dari hasil pengukuran menggunakan presisi, recall dan F-measure mendapatkan tingkat akurasi sebanyak 79\%. Sehingga untuk pengembangan penelitian berikutnya diperlukan kombinasi metode untuk memperbaiki akurasi tersebut.
\end{abstract}

Kata Kunci : Sensor, Accelometer, kondisi, jalan, Z-diff.

\begin{abstract}
Good road conditions will provide comfort and facilitate the activities of an area. The use of land transportation in Indonesia itself is very high. This causes a very high traffic load and causes damage to the road. In making an effort to reduce the number of accidents can be done by identifying the cause of the accident and the process of how to fix $i t$. One of the factors that cause accidents is the condition of the road that has holes. One solution to reduce the number of accidents is to provide information about the potholes to local authorities. So that with this information the local office can immediately follow up
\end{abstract}


on road improvements. Based on several previous studies related to the problems raised in this study will discuss the development of software by utilizing sensor accelerometers as a record of the location of hollow roads in East Semarang. This study uses the Z-diff algorithm to filter data obtained from accelerometer sensors. From the results of experiments in several districts in East Semarang which are classified as having a high level of road damage, this study found 281 potholes. From the measurement results using precision, recall and F-measure get an accuracy rate of 79\%. So that for the development of the next research, a combination of methods is needed to improve the accuracy.

Keywords: sensor, accelometer, condition, path, z-diff.

\section{PENDAHULUAN}

Kondisi jalan yang baik akan memberikan kenyamanan dan memperlancar aktifitas suatu daerah. Penggunaan transportasi darat di Indonesia sendiri sangat tinggi.Sebagai penyebab beban lalu lintas akan meningkatkan beban jalan dan bisa mengakibatkan keberlubangan pada jalan.Lubangan pada jalan dapat menimbulkan banyak gangguan yang terjadi yaitu kemacetan, keselamatan, biaya perbaikan dan biaya ganti rugi kecelakaan (Hartono, 2015).

Dalam melakukan upaya untuk mengurangi angka kecelakan dapat dilakukan untuk mengidentifikasi faktor-faktor penyebab kecelakaan dan memperbaikinya. Salah satu faktor penyebab kecelakaaan adalah dikarenakan kondisi jalan yang berlubang. Salah satunya adalah dengan menyediakan informasi tentang kondisi jalan berlubang kepada para pengguna jalan. Dengan tersedianya informasi mengenai kondisi jalan, pengguna jalan dapat lebih berhati-hati atau menghindari jalan yang sedang berlubang tersebut.

Penelitian terkait mengenai pendeteksi jalan berlubang sudah dilakukan seperti yang dilakukan oleh Artis Mednis menganalisis jalan berlubang menggunakan accelerometer yang sudah terdapat pada OS Android, dapat dioptimalisasikan pada analisis performanya dengan beberapa alghoritma (Madnis, 2011). Kemudian pada penelitian yang dilakukan oleh Nidhi Kaira di India juga pada kondisi lalu lintas mengenai kondisi jalan berlubang, dengan menggunakan sensor accelometers untuk mendeteksi kondisi jalan seperti lubang benturan, jalan yang tidak rata, dengan pengemudi jalan lurus, pengereman normal, pengereman 
mendadak, jalan belok kanan, dan kiri kemudian di klasifikasikan dengan threshold (Karla, 2014). Berbeda dengan penelitian Rudi yang membuat sebuah aplikasi pendeteksi jalan berlubang memanfaatkan akselerometer dan GPS untuk mengumpulkan data jalan, kemudian menganalisis data yang terkumpul untuk mendapatkan informasi titik-titik keberlubangan menggunakan Algoritma Pothole Patrol untuk mengenali berbagai keberlubangan jalan seperti lubang, retak, bergelombang dan deformasi (Hartono, 2017). Penelitian terkait terakhir mengenai jalan berlubang, penelitian ini mendeteksi jalan berlubang menggunakan sensor accelometer untuk mendeteksi jalan berlubang dengan memanfaatkan sensor pada smartphone dan menggunakan GPS (Chugh, 2014).

Berdasarkan dari beberapa penelitian sebelumnya yang berkaitan dengan masalah yang diangkat pada penelitian ini akan membahas tentang pemanfaatan sensor accelerometers dan maps sebagai aplikasi pencatat lokasi jalan berlubang yang perlu di perbaiki, sehingga dengan adanya informasi tersebut, maka dinas setempat dapat segera menindaklanjuti perbaikan jalan. Metode penelitian ini akan menggunakan metode kombinasi dari penelitian sebelumnya yaitu Algoritma ZDiff yang sudah di lakukan penelitian sebelumnya memiliki akurasi $92 \%$. Diharapkan dari menggunakan metode Z-Diff dapat menghasilkan tingkat akurasi yang lebih baik. Sehingga dapat dimanfaatkan untuk mendapatkan data dan informasi jalan berlubang.

\section{METODE PENELITIAN}

\section{Alghoritma Z-Diff Algoritm}

Alghoritma Z-Diff merupakan algoritma yang mempertimbangkan perbedaan nilai pada sumbu Z-Axis yang dihasilkan dari accelerometer. Karena nilai sumbu Z-Axis banyak mengalami penurunan atau kenaikan yang disebabkan dari nilai kecepatan antara waktu $\mathrm{t}_{\mathrm{i}, \mathrm{j}-1}$ dan waktu $\mathrm{t} \mathrm{i}, \mathrm{j}$. Algoritma ini membutuhkan nilai ambang batas untuk mendeteksi lubang. Nilai ambang batas yang akan diperoleh adalah dari nilai maksimum sumbu Z-Axis untuk percobaan. Rumus yang digunakan untuk menentukan nilai ambang batas sebagai berikut : 


$$
\theta_{2}=\min \max \frac{\left|g_{a, j, i}-g_{a, i, j-1}\right|}{t_{i, j}-t_{i, j-1}}
$$

Kemudian setelah mendapatkan nilai ambang batas, algoritma ini akan membandingkan dengan 2 nilai yaitu jika hasil dari selisih nilai sumbu Z-Axis dan selisih nilai antara waktu t i,j-1 dan waktu t i,j lebih besar dari nilai ambang batas maka nilainya 1 yang artinya lubang terdeteksi. Rumus yang digunakan sebagai berikut :

$$
f_{2}\left(g_{a, i, j}\right)=\left\{\begin{array}{c}
1, \quad \frac{\left|g_{a, i, j}-g_{a, i, j-1}\right|}{t_{i, j}-t_{i, j-1}} \geq \theta_{2} \\
\text { other, }
\end{array}\right.
$$

Where $\mathrm{a}=1,1 \leq i \leq n, i \in N, j \geq j \in N$

Tahapan penerapan algoritma yang akan dilakukan seperti berikut :
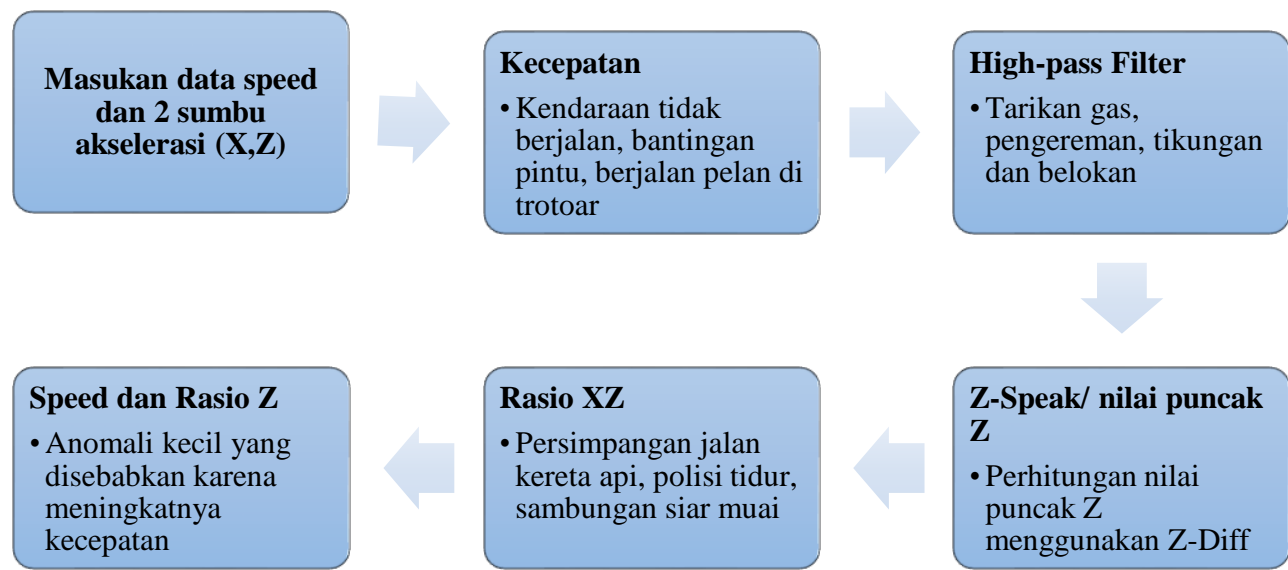

Z-Speak/ nilai puncak

$\mathbf{Z}$

- Perhitungan nilai

puncak Z

menggunakan Z-Diff

Keluaran X,Z filtered

Gambar 1.Tahapan Penerapan algoritma 
a. Kecepatan yaitu tapan yang melakukan seleksi kecepatan, jika kecepatan nol atau kendaraan sangat pelan, maka data akan dibuang. Pada penelitian ini menggunakan batas kecepatan $\geq 10 \mathrm{~km} / \mathrm{jam}$.

b. High-pass Filter yaitu penghapusan sinyal dengan frekuensi rendah pada percepatan sumbu $\mathrm{x}$ dan $\mathrm{z}$. Beberapa kejadian yang menghasilkan frekuensi rendah seperti tarikan gas, tikungan, belokan, pengereman dan beberapa perubahan kecil yang disebabkan orientasi perangkat smartphone. Penelitian ini menggunakan batas minimal sumbu $\mathrm{x} \geq 0$ dan sumbu $\mathrm{z} \geq 10$.

c. Puncak sumbu $Z$ ( $t z$ )yaitu menentukan nilai batas sumbu $Z$ yang akan menjadi acuan identifikasi jalan berlubang. Untuk menentukan nilai batas sumbu $\mathrm{Z}$ akan menggunakan algoritma Z-Diff . Algoritma Z-Diff menggunakan ambang batas $\left(\theta_{2}\right)$ yang diambil dari nilai minimum dari nilai maksimum sumbu $\mathrm{z}$ dengan rumus $\mathrm{z}-\mathrm{z}-1 / \mathrm{t}-\mathrm{t}-1$. Kemudian untuk memfilter data jika hasil dari perhitungan rumus z-z-1/t-t-1 $\geq \theta_{2}$ maka data akan direkam.

d. Rasio XZ yaitu filter dari kedua sumbu dengan menggunakan perbandingan dengan cara menentukan nilai tx yang menjadi batas identifikasi anomali jenis jalan berlubang dengan jenis jalan normal seperti polisi tidur, sambungan suar muai (jembatan) dan persimpangan jalan raya. Data akan dibuang jika sumbu data sumbu $\mathrm{X}$ dibagi dengan sumbu $\mathrm{Z}$ hasilnya kurang dari $t x$.

e. Kecepatan dan rasio z yaitu tahapan dimana identifikasi kerusakan jalan dengan membandingkan data kecepatan dengan sumbu Z. Jika kendaraaan melaju dengan kecepatan tinggi, maka nilai $\mathrm{Z}$ yang dihasilkan akan semakin tinggi. Jadi jika nilai Z yang tinggi karena efek dari kecepatan maka data akan dibuang dengan rumus pembanding $Z<$ ts $X$ speed. 


\section{HASIL DAN PEMBAHASAN}

\section{Data Training dan Data Testing}

Data yang di dapatkan untuk penelitian ini adalah di Semarang Timur, meliputi dengan dataset untuk daerah Muktiharjo Lor, Palebon, Banget Ayu Wetan, Tlogosari Kulon, Tlogosari Wetan, Gayamsari, Pedurungan dengan 281 titik, dengan mencari nilai ambang batas minimal $-0,01272$, dengan menggunakan sensor accelometer, untuk mengidentifikasi jalan berlubang, kemudian data yang di dapatkan akan di jadikan sebagai saran untuk dinas setempat dapat segera menindaklanjuti perbaikan jalan.

Pada gambar 2 adalah grafik dari pengambilan data menggunakan sensor accelometer di Semarang Timur, grafik dengan sumbu $\mathrm{x}, \mathrm{y}, \mathrm{z}$ dan dengan mencari nilai ambang betas atau tetha menghasilkan, jika nilai lebih dari ambang batas -0,01272 maka terdeteksi jalan berlubang.

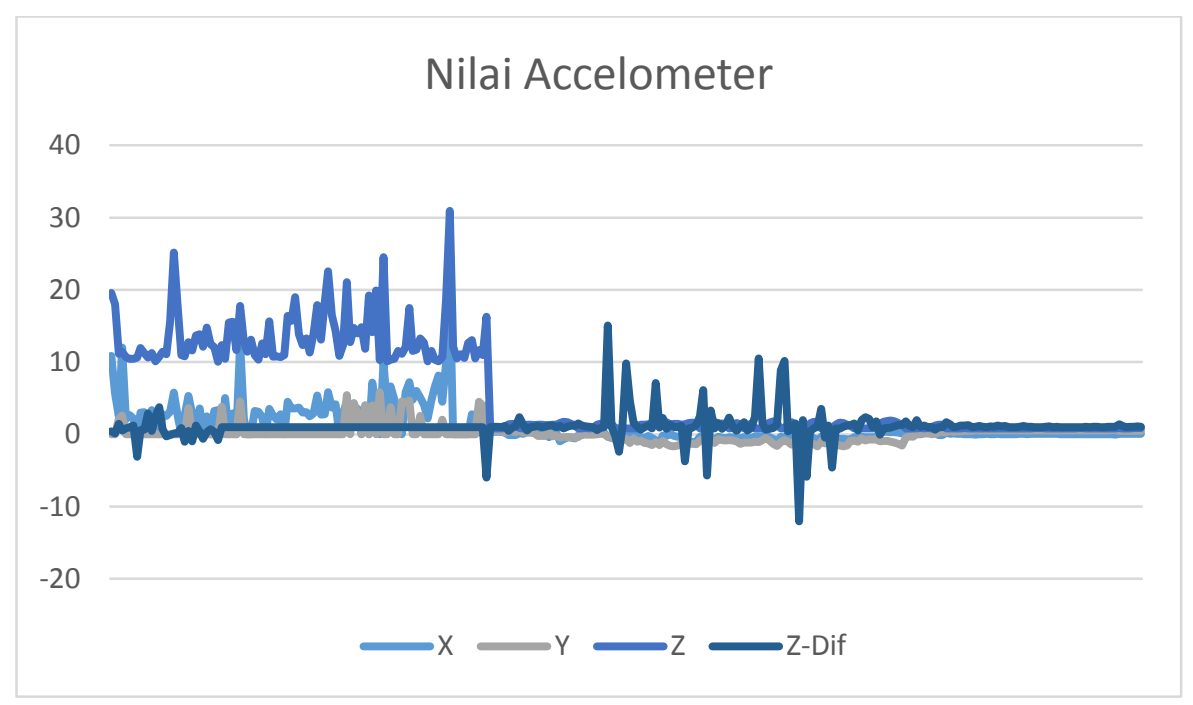

Gambar 2. Hasil Dataset Menggunakan Sensor Accelometer 


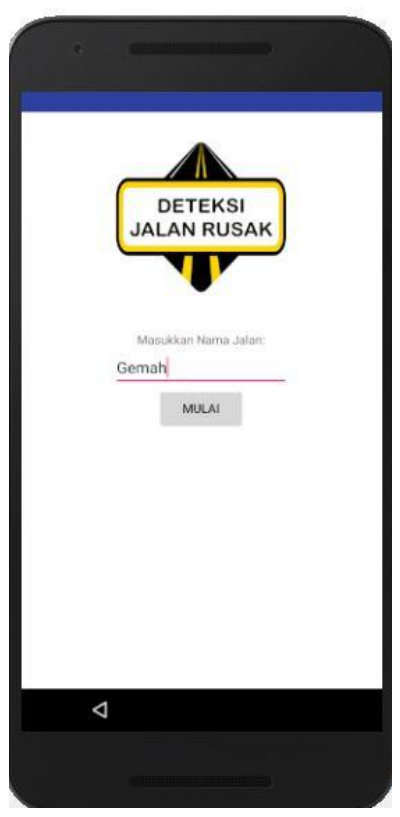

Gambar 3. Halaman Penyimpanan nama jalan Sistem Deteksi Kondisi Jalan

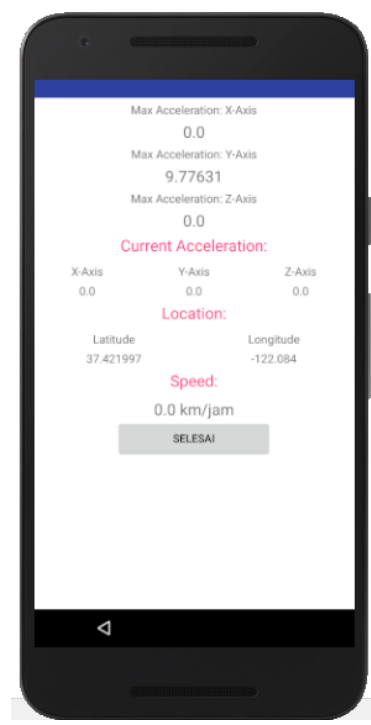

Gambar 4. Tampilan Aplikasi Sistem Deteksi Kondisi Jalan 


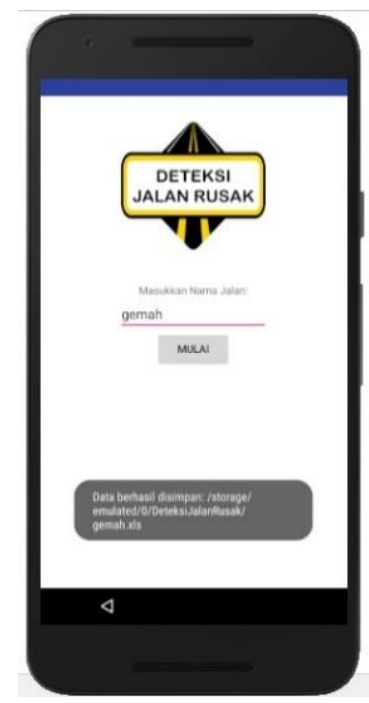

Gambar 5. Tampilan Menyimpan ke Database dalam bentuk excel

Pada gambar 4 aplikasi accelometer ini digunakan untuk mencatat nama jalan berlubang, tampilan menu utama dari aplikasi pada gambar 4 tampilan ini di gunakan untuk mendeteksi sumbu $\mathrm{x}$, y dan $\mathrm{z}$ dari hasil rekaman sensor accelometer, aplikasi ini juga mendeteksi location (Latitude dan Longitude), dan untuk menghitung nilai Zdiff menggunakan rumus z-z-1/t-t-1. Kemudian untuk memfilter data jika z-z-1/t-t- $1 \geq{ }^{\theta_{2}}$ maka data akan direkam. Dan menu tersebut di tersimpan di excel pada gambar 5 .

\section{Pengujian dan Akurasi}

Untuk mengukur kemampuan system dalam mengidentifikasi permukaan jalan, penelitian ini akan menggunakan perhitungan presisi, recall dan F-Measure. Pada penelitian ini menggunakan percobaan jalan dibeberapa kecamatan wilayah Semarang Timur. Dari percobaan penelitian ini menggunakan 281 titik jalan berlubang yang tersebar hasil percobaan system telah berhasil merekam. Berikut matrix darihasil percobaan tersebut:

Tabel 1. Matrix Hasil Pengumpulan Data

\begin{tabular}{|c|c|c|}
\hline Jenis & True & False \\
\hline Jalan Berlubang & 220 & 90 \\
\hline Bukan Jalan Berlubang & 61 & 20 \\
\hline
\end{tabular}




$$
\begin{aligned}
& \text { Recall }=\frac{220}{220+90}=0,709 \\
& \text { Precision }=\frac{220}{220+20}=0,916 \\
& \text { F-Measure }=\frac{2 * \text { Recall } * \text { Precision }}{\text { Precision }+ \text { Recall }}=\frac{2 * 0,709 * 0,916}{0,709+0,916}=\frac{1,298}{1,625}=0,79
\end{aligned}
$$

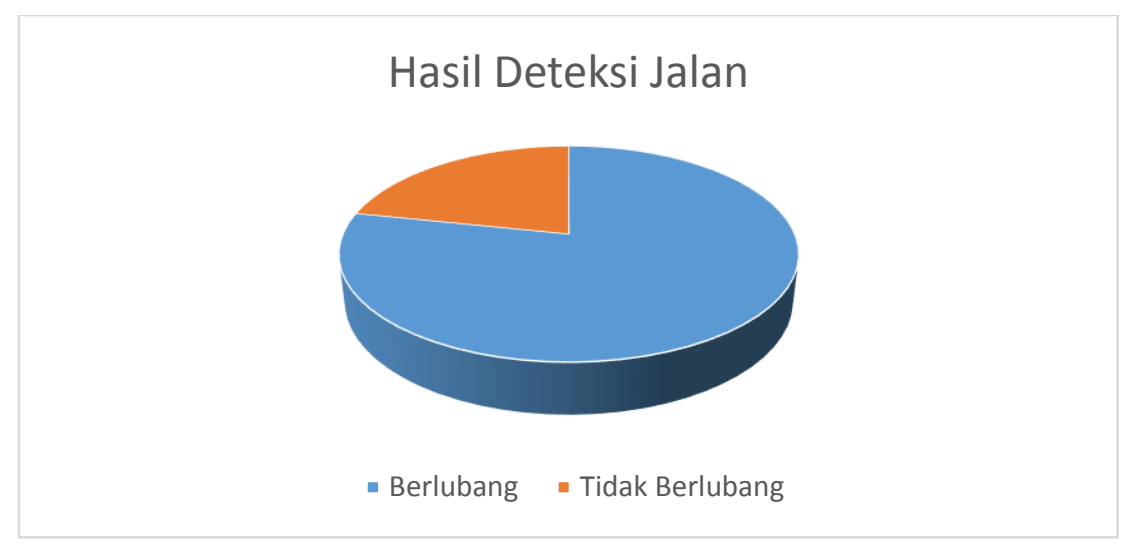

Gambar 5. Hasil Deteksi Jalan Berlubang

Hasil nilai diatas menunjukkan nilai akurasi recall sebanyak 70\%, presisi $91 \%$ dan menghasilkan F-Measure sebanyak 79\% yang artinya bahwa sistem memiliki akurasi yang cukup tinggi dalam mengidentifikasi jalan berlubang atau jalan yang perlu diperbaiki. Hal ini disebabkan karena kepadatan jalan raya pada saaat saat pengambilan data.

\section{KESIMPULAN DAN SARAN}

Dari penelitian ini dapat di simpulkan bahwa aplikasi ini akan di fokuskan untuk mencatat dan mendeteksi jalan berlubang, menggunakan sensor accelometer dan alghoritma Z-Diff untuk mengidentifikasi permukaan jalan yang berlubang, dengan sensor accelometer sumbu $\mathrm{x}, \mathrm{y}, \mathrm{z}$ kemudian menetukan tetha dan menghitung nilai zdiff untuk menghitung nilai ambang batas. Sistem tersebut dilengkapi sensor GPS yang dapat memberikan informasi mengenai titik lokasi jalan yang perlu diperbaiki. Percobaan sistem dilakukan pada wilayah Semarang Timur. Dari hasil percobaan sistem dapat mengidentifikasi 281 titik lokasi jalan rusak yang perlu diperbaiki. Tingkat akurasi yang dihasilkan dari sistem sebanyak 
$79 \%$ yang artinya sistem cukup stabil dalam mengidentifikasi kondisi permukaan jalan. Untuk pengembangan penelitian selanjutnya diharapkan dapat meningkatkan akurasi dengan menggunakan metode yang berbeda.

\section{DAFTAR PUSTAKA}

Hartono, R., Wibisono, Y., \& Sukamto, R. A. (2017). Damropa (Damage Roads Patrol): Aplikasi Pendeteksi Jalan Berlubang Memanfaatkan Accelerometer pada Smartphone.

Madnis, A., Strazdins, G., Zviedris, R., Kanonirs, G., \& Selavo, L. (2011, June). Real time pothole detection using android smartphones with accelerometers. In Distributed Computing in Sensor Systems and Workshops (DCOSS), 2011 International Conference on (pp. 1-6). IEEE.

Kalra, Nidhi, Gunjan Chugh, and Divya Bansal. "Analyzing driving and road events via smartphone." International Journal of Computer Applications 98.12 (2014): 5-9.

Chugh, G., Bansal, D., \& Sofat, S. (2014). Road condition detection using smartphone sensors: A survey. International Journal of Electronic and Electrical Engineering, 7(6), 595-602. 